\title{
Cryoballoon ablation for paroxysmal atrial fibrillation: mid-term outcome evaluated by ECG monitoring with an implantable loop recorder.
}

\author{
Riccardo Maj ${ }^{1}$, Sergio De Ceglia ${ }^{1}$, Elena Piazzi ${ }^{1}$, Mattia Pozzi ${ }^{1}$, Elisabetta Montemerlo ${ }^{1}$, \\ Mirko Casiraghi ${ }^{1}$, Marianna Fienga ${ }^{1}$, Sara Gressoni ${ }^{1}$, and Giovanni Rovaris ${ }^{1}$ \\ ${ }^{1}$ San Gerardo Hospital
}

November 14, 2020

\begin{abstract}
BACKGROUND The success rate after cryoballoon ablation (CB-A) performed for paroxysmal atrial fibrillation (PAF) might be underestimated by traditional noninvasive monitoring techniques. The purpose of this study was to evaluate the mid-term outcome of CB-A in patients with PAF implanted with an implantable loop recorder (ILR) after the procedure. METHODS Between January 2017 and March 2019, all patients who underwent CB-A for PAF and who were subsequently implanted with an ILR were retrospectively included. All devices were equipped with remote monitoring. All ILR-documented atrial tachycardia (AT) or AF episodes [?] 6 minutes were considered as recurrence; both true and false episodes were collected. A 3-month post-procedural blanking period (BP) was applied. RESULTS A total of 102 patients (77 male, mean age 60.6 \pm 9.6 years) who underwent pulmonary vein isolation (PVI) by CB-A were included; mean time from first diagnosis of AF to PVI was $51.5 \pm 46.9$ months. Mean follow-up was $29.3 \pm 8.1$ months; at 12 -month follow-up, the success rate was $64.7 \%$, while at 2-year follow-up, freedom from AT/AF recurrences was achieved in $44.1 \%$ of the patients. In the follow-up, a total of 4987 ECG strips were analyzed; true-positive episodes were confirmed in 2026 cases (40.6\%), while 2961 episodes (59.4\%) were considered false-positive. CONCLUSION In patients with PAF implanted with an ILR, CB-A results in freedom from any $\mathrm{AT} / \mathrm{AF}$ recurrence in $64.7 \%$ of patients at 12 -month follow-up and in $44.1 \%$ of patients when evaluated at 2 -year. Careful adjudication of all ILR-documented AF episodes is required to avoid misdiagnosis.
\end{abstract}

\section{Hosted file}

Paper.pdf available at https://authorea.com/users/375739/articles/492908-cryoballoonablation-for-paroxysmal-atrial-fibrillation-mid-term-outcome-evaluated-by-ecgmonitoring-with-an-implantable-loop-recorder

\section{Hosted file}

Figures.pdf available at https://authorea.com/users/375739/articles/492908-cryoballoonablation-for-paroxysmal-atrial-fibrillation-mid-term-outcome-evaluated-by-ecgmonitoring-with-an-implantable-loop-recorder

\section{Hosted file}

Tables.pdf available at https://authorea.com/users/375739/articles/492908-cryoballoonablation-for-paroxysmal-atrial-fibrillation-mid-term-outcome-evaluated-by-ecgmonitoring-with-an-implantable-loop-recorder 